\title{
Potential role of estradiol and progesterone in insulin resistance through constitutive androstane receptor
}

\author{
Hisashi Masuyama and Yuji Hiramatsu \\ Department of Obstetrics and Gynecology, Okayama University Graduate School of Medicine, Dentistry and Pharmaceutical Sciences \\ 2-5-1 Shikata, Kita-ku, Okayama 700-8558, Japan \\ (Correspondence should be addressed to H Masuyama; Email: masuyama@cc.okayama-u.ac.jp)
}

\begin{abstract}
Normal pregnancy is characterized by insulin resistance, which contributes to the development of gestational diabetes mellitus and preeclampsia by incompletely understood mechanisms. The constitutive androstane receptor (CAR) may participate in insulin resistance in pregnancy, and sex steroids, estradiol $\left(\mathrm{E}_{2}\right)$ and progesterone, may also be involved. We applied glucose and insulin tolerance tests and measured the expression of gluconeogenic and lipogenic genes in the livers of oophorectomized mice treated with $E_{2}$ and progesterone with or without CAR ligands. We also investigated how $\mathrm{E}_{2}$ and progesterone affected CAR-mediated signaling and the activity of transcription factors in gluconeogenesis in vitro. Mice with the concentrations of $E_{2}$ and progesterone within normal physiological range during pregnancy exhibited increased insulin resistance along with increased expression of gluconeogenic and lipogenic genes, and CAR activation rescued the abnormal glucose metabolism. In HepG2 cells, CAR ligands suppressed the gluconeogenic and lipogenic gene expression in the presence of $\mathrm{E}_{2}$ and/or progesterone. DNA affinity immunoblotting and chromatin immunoprecipitation assay revealed that CAR ligand enhanced the recruitment of the gluconeogenic transcription factors, forkhead box $\mathrm{O} 1$ (FOXO1) and hepatocyte nuclear factor $4 \alpha$ (HNF4 $\alpha$ ), but sex steroids suppressed these recruitments on the CAR responsive element. Moreover, CAR ligand suppressed the recruitment of FOXO1 and HNF4 $\alpha$ on their responsive element in gluconeogenic gene promoters and $E_{2}$ and progesterone augmented these recruitments on their responsive element. Taken together, these findings suggest that the activation of CAR-mediated signaling may ameliorate insulin resistance under relatively high concentrations of $\mathrm{E}_{2}$ and progesterone, which were compatible with pregnancy via decreased activities of transcription factors in gluconeogenesis in combination with CAR.
\end{abstract}

Journal of Molecular Endocrinology (2011) 47, 229-239

\section{Introduction}

Normal human pregnancy is characterized by mild fasting hypoglycemia, postprandial hyperglycemia, and hyperinsulinemia (Cunningham et al. 2010). These responses are consistent with a pregnancy-induced state of insulin resistance, the purpose of which is likely to be to ensure a sustained postprandial supply to the fetus (Cunningham et al. 2010). Indeed, the insulin sensitivity in normal pregnant women is $45-70 \%$ lower during the course of gestation compared with non-pregnant women (Catalano et al. 1991, Butte 2000, Freemark 2006). In addition, an increase in insulin resistance contributes to the development of gestational diabetes mellitus and preeclampsia (Kaaja et al. 1999, Seely \& Solomon 2003, Kaaja \& Greer 2005). However, the mechanism responsible for the insulin resistance during pregnancy is not completely understood. This condition has been attributed to the effects of human placental lactogen, cortisol, human placental GH and prolactin (Ryan \& Enns 1988). However, increased levels of free fatty acids, peroxisome proliferator-activated receptors, tumor necrotic factor- $\alpha$, adiponectin, and resistin have all been implicated in insulin resistance in pregnancy (Kaaja \& Greer 2005). In addition to some placental hormones that decrease insulin sensitivity, estradiol $\left(\mathrm{E}_{2}\right)$ and progesterone, could be involved in the gestation-induced insulin resistance because the relatively high concentrations of these hormones, $\mathrm{E}_{2}(100-200 \mathrm{pg} / \mathrm{ml})$ and progesterone $(100-200 \mathrm{ng} / \mathrm{ml})$, which are within physiological ranges during pregnancy in their experiments, reduce insulin sensitivity (Ryan \& Enns 1988, Livingstone \& Collison 2002, Barros et al. 2008).

The constitutive androstane receptor (CAR) is an orphan nuclear receptor. It was originally characterized as a nuclear receptor that can activate an empirical set of retinoic acid response elements without retinoic acid (Baes et al. 1994, Choi et al. 1997), and can be activated in response to xenochemical exposure, including phenobarbital (PB)-stimulated activation of a response element, NR1, found in the human and mouse cytochrome p450 2B (CYP2B) genes (Honkakoski et al. 1998, Sueyoshi et al. 1999). This PB response enhancer module is also located in the upstream region of the uridine diphosphate- 5 -glucuronosyltransferase 
1A1 (UGT1A1) gene and is activated by CAR (Sugatani et al. 2001, Masuyama et al. 2010). In addition, activation of the bilirubin clearance pathway by CAR ligands is abolished in CAR-null mice (Huang et al. 2003), suggesting that the CAR-UGT1A1 pathway may play an important role in bilirubin clearance. Moreover, recent studies have linked CAR to lipid and glucose metabolism. Activation of CAR suppresses lipid metabolism and lowers serum triglyceride by reducing the protein levels of the active form of a lipogenic transcription factor, sterol regulatory element-binding protein 1 (SREBP-1; Roth et al. 2008). The key hepatic gluconeogenic enzymes phosphoenolpyruvate carboxykinase (PEPCK) and glucose-6-phosphatase (G6Pase) were reported to be repressed in PB-treated mice and these suppressions were CAR-dependent (Ueda et al. 2002). Recent in vivo studies have demonstrated that activation of CAR improves insulin sensitivity via glucose and lipid metabolic pathways including PEPCK, G6Pase, SREBP-1, and stearoyl-CoA desaturase 1 (SCD-1), a key enzyme for the synthesis of unsaturated fatty acids (Dong et al. 2009, Gao et al. 2009).

CAR has been shown to participate in insulin resistance, and sex steroids, estrogen and progesterone, may also be involved in insulin resistance during pregnancy (Ryan \& Enns 1988, Livingstone \& Collison 2002, Barros et al. 2008, Dong et al. 2009, Gao et al. 2009). Therefore, we examined glucose tolerance test (GTT) and insulin tolerance test (ITT) and measured the expression of gluconeogenic and lipogenic genes in the livers of oophorectomized ICR mice treated with $\mathrm{E}_{2}$ and progesterone in the presence or absence of CAR ligands. We also investigated how $\mathrm{E}_{2}$ and progesterone affected CAR-mediated signaling and the activity of transcription factors in gluconeogenesis in vitro. The mechanisms responsible for the effects of sex steroids, $\mathrm{E}_{2}$ and progesterone on glucose metabolism and insulin resistance via CAR-mediated signaling, were investigated in vitro.

\section{Materials and methods}

\section{Materials}

$\mathrm{E}_{2}$, progesterone, 1,4-bis[2-(3,5-dichloropyridyloxy)] benzene (TCPOBOP), 6-(4-chlorophenyl)imidazo[2,1b] [1,3] thiazole-5-carbaldehyde $O$-(3,4-dichlorobenzyl) oxime (CITCO), PB, and pure corn oil were purchased from Sigma-Aldrich. CITCO and TCPOBOP are the only ligands shown to specifically bind to human and mouse CAR and regulate the target genes respectively (Sueyoshi et al. 1999, Maglich et al. 2003). HepG2 cells were obtained from the Health Science Research Resources Bank (Osaka, Japan).

\section{Animal procedures}

Female ICR mice at 8 weeks of age were obtained from Charles River Co. Ltd (Tokyo, Japan), and six mice were examined per group for all in vivo experiments. To avoid the effect of menstrual cycle and do experiments under same hormonal conditions, we employed oophorectomized mice for this study. ICR mice were oophorectomized at 8 weeks of age and received once-weekly i.p. injections of TCPOBOP $(0.5 \mathrm{mg} / \mathrm{kg})$ or corn oil with or without twice-daily s.c. injections of $E_{2}(50 \mu \mathrm{g} / \mathrm{kg})$ and progesterone $(3 \mathrm{mg} / \mathrm{kg})$, which were determined by previous reports (Song et al. 2001, Barros et al. 2008), for 2 weeks from 10 weeks of age. This dose gave plasma concentrations $\left(\mathrm{E}_{2}=70 \cdot 4 \pm 6 \cdot 9 \mathrm{pg} / \mathrm{ml}\right.$, progesterone $=84 \cdot 2 \pm 9 \cdot 1 \mathrm{ng} / \mathrm{ml}, \quad n=6)$ similar to those found in late pregnancy (Masuyama et al. 2001, Song et al. 2001). Because the concentrations of $\mathrm{E}_{2}$ and progesterone might change with different strain of mice, age and differences in detection methods of hormones, we also examined plasma concentration of $\mathrm{E}_{2}$ and progesterone of oophorectomized vehicle-treated control mice $\left(\mathrm{E}_{2}=1.4 \pm 0.3 \mathrm{pg} / \mathrm{ml}\right.$, progesterone $=3 \cdot 1 \pm 0 \cdot 7 \mathrm{ng} / \mathrm{ml}, n=6$ ), pregnant ICR mice on day 18 of gestation in normal pregnant mice $\left(\mathrm{E}_{2}=75.9\right.$ $\pm 9 \cdot 3 \mathrm{pg} / \mathrm{ml}$, progesterone $=80 \cdot 5 \pm 5 \cdot 9 \mathrm{ng} / \mathrm{ml}, n=6$ ) and non-pregnant female mice at 8 weeks of age before oophorectomy $\left(E_{2}=7 \cdot 3 \pm 2 \cdot 4 \mathrm{pg} / \mathrm{ml}\right.$, progesterone $=9 \cdot 2 \pm 1.9 \mathrm{ng} / \mathrm{ml}, n=6)$ in ICR mice tested in this study. The animals were killed under ether anesthesia at 12 weeks of age and their livers were removed, immediately frozen and stored at $-70^{\circ} \mathrm{C}$ until analysis. Total RNA was extracted using TRIzol reagent (Life Technologies, Inc.), according to the manufacturer's instructions. The mice were kept in a temperature- and light-controlled room with free access to normal diet (12\% fat, $28 \%$ protein, and $60 \%$ carbohydrate, Oriental yeast Co., Tokyo, Japan) and water except when undergoing GTTs and ITTs. All procedures performed on the mice were approved by the Institutional Animal Care and Use Committee of Okayama University.

\section{GTT, ITT and measurements of the insulin and total triglyceride levels}

Mice at 12 weeks of age were fasted for $16 \mathrm{~h}$ before receiving an i.p. injection of D-glucose $(2 \mathrm{~g} / \mathrm{kg}$ body weight) for the GTT or for $4 \mathrm{~h}$ before receiving an i.p. injection of human insulin $(1.0 \mathrm{U} / \mathrm{kg}$ body weight) for the ITT. Blood samples from tail vein were taken before and at 30, 60, 90, and $120 \mathrm{~min}$ after the injection. The blood glucose levels were measured by the glucose oxidase method using a Medisafe automated analyzer (Termo, Tokyo, Japan). Fasting insulin, $\mathrm{E}_{2}$, progesterone, and total triglyceride levels were determined using ELISA kits (Morinaga Institute of Biological 
Sciences, Inc., Yokohama, Japan, Cayman Chemicals Co., Ann Arbor, MI, USA). The homeostasis model assessment as an index of insulin resistance (HOMAIR) was calculated as the fasting insulin concentration $(\mu \mathrm{U} / \mathrm{ml}) \times$ fasting glucose concentration $(\mathrm{mg} / \mathrm{dl}) / 405$ (Matthews et al. 1985).

\section{Cell culture and RNA interference}

HepG2 cells were cultured in DMEM without phenol red supplemented with $10 \%$ charcoal stripped fetal bovine serum. The medium and fetal bovine serum were purchased from Invitrogen Corp. A small interfering RNA (siRNA) cocktail targeting human $C A R$ was purchased from B-Bridge International, Inc. (Mountain View, CA, USA) and contained three siRNAs as described previously (Masuyama et al. 2010). A negative control cocktail consisting of non-complementary human, mouse, and rat and liposome sequences for siRNA transfection was also purchased from B-Bridge International, Inc. Cells were transfected with the CAR siRNAs or control siRNAs using siFECTOR according to the manufacturer's protocol (B-Bridge International, Inc.).

\section{RT-PCR and real-time quantitative PCR}

Total RNA was extracted from HepG2 cells and mouse livers using TRIzol reagent (Life Technologies, Inc.). To confirm the downregulation of CAR expression by RNA interference, RT-PCR was performed by an RNA PCR kit (TaKaRa Co. Ltd, Kyoto, Japan) according to the manufacturer's protocol. Amplification of the CAR sequence was carried out using a GeneAmp PCR System 9700 (Applied Biosystems, Inc., Foster City, CA, USA). The number of PCR cycles required to produce PCR products in the linear logarithmic phase of the amplification curve was determined. The PCR products were electrophoresed in $3 \%$ agarose gels and visualized by staining with ethidium bromide. To measure the mRNA levels of PEPCK, G6Pase, SREBP-1, SCD-1, CYP2C9, and CYP2B6, real-time quantitative PCR was performed by a StepOne Real-time PCR System and a TaqMan RNA-to-CT Gene Kit (Applied Biosystems). Specific primers for the human CAR, PEPCK, G6Pase, SREBP-1, SCD-1, CYP2C9, CYP2B6, and $\beta$-actin and mouse CAR, PEPCK, G6Pase, $S R E B P-1$, and $S C D-1$ gene sequences were purchased from Applied Biosystems. Aliquots (25 ng) of the RNA samples were assayed using $15 \mathrm{pmol}$ of gene-specific primers and 5 pmol of gene-specific probes in triplicate. As internal controls, the human or mouse $\beta$-actin mRNA levels were measured using a pre-developed TaqMan primer and a probe mixture (Applied Biosystems). Normalization of the data was accomplished by quantifying the amount of amplified cDNA products by calculating the ratio of the amount of cDNA relatives to the amount of $\beta$-actin cDNA.

\section{Transient transfection studies}

The (NR1) ${ }^{3}$-tk-CAT vector was generated by insertion of three copies of double-stranded oligonucleotides containing the NR1 site ( $5^{\prime}$-gatcACTGTACTTTCCTGACCTTGgatc-3') as described previously (Sueyoshi et al. 1999, Masuyama et al. 2010). HepG2 cells were cotransfected with $1 \mathrm{mg}$ of a reporter gene construct, $(\mathrm{NR} 1)^{3}$-tk-CAT or tk-CAT. In all experiments, liposomemediated transfections were accomplished using Lipofectamine (Life Technologies, Inc.) according to the manufacturer's instructions. The transfected cells were treated with ethanol vehicle alone or with the CAR ligands PB $(1 \mathrm{mM})$ or CITCO $(1 \mu \mathrm{M})$, with or without $\mathrm{E}_{2}(100 \mathrm{nM})$, and/or progesterone $(1 \mu \mathrm{M})$ for $36 \mathrm{~h}$. Cell extracts were prepared and assayed for CAT activity. The amount of CAT was determined using a CAT ELISA Kit (Roche Diagnostics Co.) according to the manufacturer's instructions.

\section{Western blot analysis}

Whole cell extracts were obtained from HepG2 cells using M-PER Mammalian Protein Extraction Reagents (Pierce Chemical Co., Rockford, IL, USA) according to the manufacturer's protocol, and stored at $-80^{\circ} \mathrm{C}$ until analysis. The protein samples were solubilized in SDS buffer $(0 \cdot 05 \mathrm{M}$ Tris-HCl pH $6 \cdot 8,2 \%$ SDS, $6 \%$ mercaptoethanol, and $10 \%$ glycerol) and analyzed by western blotting using a goat polyclonal antibody against CAR (1:1000 dilution), a mouse monoclonal antibody against $\beta$-actin (1:2000), HRP-conjugated rabbit anti-goat or anti-mouse secondary antibody (1:10 000 dilution; Santa Cruz Biotechnology, Inc., Santa Cruz, CA, USA), nitrocellulose membranes (Hybond-ECL, GE Healthcare, USA), and chemiluminescent detection reagent (ECL Plus Western blotting detection reagents; GE Healthcare, Amersham, UK) as described previously (Masuyama \& MacDonald 1998).

\section{DNA affinity immunoblotting}

Nuclear extracts were obtained from HepG2 cells using nuclear and cytoplasmic extraction reagents according to the manufacture's protocol (Thermo Fisher Scientific, Inc., Waltham, MA, USA). As previously described (Moore et al. 2000), aliquots $(200 \mu \mathrm{g})$ of the nuclear extracts from HepG2 cells were incubated at $4{ }^{\circ} \mathrm{C}$ for 30 min with a DNA binding reaction mixture containing $25 \mathrm{nM}$ biotin-labeled NR1, $2 \mathrm{mg}$ of poly $(\mathrm{dI} / \mathrm{dC}), 5 \mathrm{mM}$ dithiothreitol, and $40 \mu \mathrm{l}$ of $10 \times$ DNA binding buffer (200 mM Tris- $\mathrm{HCl} \mathrm{pH} 7 \cdot 2,10 \mathrm{mM}$ EDTA, $1 \%$ Triton X-100, and $40 \%$ glycerol). For rescue experiments, HepG2 cells were cotransfected with various amounts of pcDNA3-steroid receptor coactivator-1 (SRC-1) or pcDNA3 expression vector alone. 
A human SRC-1 cDNA was subcloned into the pcDNA3 expression vector (Invitrogen) as described previously (Masuyama et al. 2005). DNA/protein complexes were captured with $0.1 \mathrm{mg}$ of magnetic streptavidin beads (Dynabeads; Dynal Biotech, Oslo, Norway) at $4{ }^{\circ} \mathrm{C}$ for $30 \mathrm{~min}$. The beads were drawn into a pellet using a magnet and washed three times with DNA binding buffer. The bound proteins were eluted from the magnetic beads by heating at $70{ }^{\circ} \mathrm{C}$ in $20 \mathrm{ml}$ of SDS buffer $(0.05 \mathrm{M}$ Tris-HCl pH 6.8, 2\% SDS, 6\% mercaptoethanol, and $10 \%$ glycerol) and analyzed by western blotting using rabbit polyclonal antibodies against CAR (1:1000 dilution), SRC-1 (1:500 dilution), forkhead box O1 (FOXO1; 1:500 dilution), hepatocyte nuclear factor $4 \alpha$ (HNF4 $\alpha ; 1: 500$ dilution), estrogen receptor $\alpha(\mathrm{ER} \alpha ; 1: 1000$ dilution) and progesterone receptor (PR; 1:1000 dilution), and HRP-conjugated goat anti-rabbit secondary antibody (1:10 000 dilution; Santa Cruz Biotechnology, Inc.) and chemiluminescent detection reagent (ECL Plus Western blotting detection reagents, GE Healthcare).

\section{Chromatin immunoprecipitation assays}

Chromatin immunoprecipitation (ChIP) assays were performed by a ChIP assay kit (Upstate Biotechnology,
Lake Placid, NY, USA) according to the manufacture's protocol. Briefly, HepG2 cells were grown to $90 \%$ confluent, were treated with ethanol vehicle alone or with CITCO $(1 \mu \mathrm{M})$, with or without $\mathrm{E}_{2}(100 \mathrm{nM})$, and/or progesterone $(1 \mu \mathrm{M})$ for $48 \mathrm{~h}$, were incubated with $1 \%$ formaldehyde at room temperature for $10 \mathrm{~min}$ and subjected to sonication to reduce DNA length to $0 \cdot 3-1 \cdot 0 \mathrm{~kb}$. Chromatin was precleared in the presence of $20 \mu \mathrm{l}$ of normal serum, $2 \mu \mathrm{g}$ of salmon sperm DNA, and $80 \mu \mathrm{l}$ of a $25 \%$ protein A-agarose slurry. Precleared chromatin samples were subjected to immunoprecipitation at $4{ }^{\circ} \mathrm{C}$ overnight in the presence of $2 \mu \mathrm{g}$ of goat polyclonal antibody against CAR, rabbit polyclonal antibodies against SRC-1, FOXO1, HNF4 $\alpha$, ER $\alpha$, and PR (Santa Cruz Biotechnology, Inc.), or nonimmune rabbit IgG. After collecting the complex by incubation with $60 \mu \mathrm{l}$ of a $25 \%$ protein A-Sepharose slurry and centrifugation, the beads were washed five times, and the chromatin immune complex was eluted. After reversing the cross-links, DNA was purified and used as a template in PCR. PCR was performed by primer sets specific for the CAR responsive element in the CYP2C9 promoter (Surapureddi et al. 2008), the HNF $4 \alpha$ responsive element in the PEPCK promoter (Bhalla et al. 2004), and FOXO1 binding site in the G6Pase promoter (Vander Kooi et al. 2003).
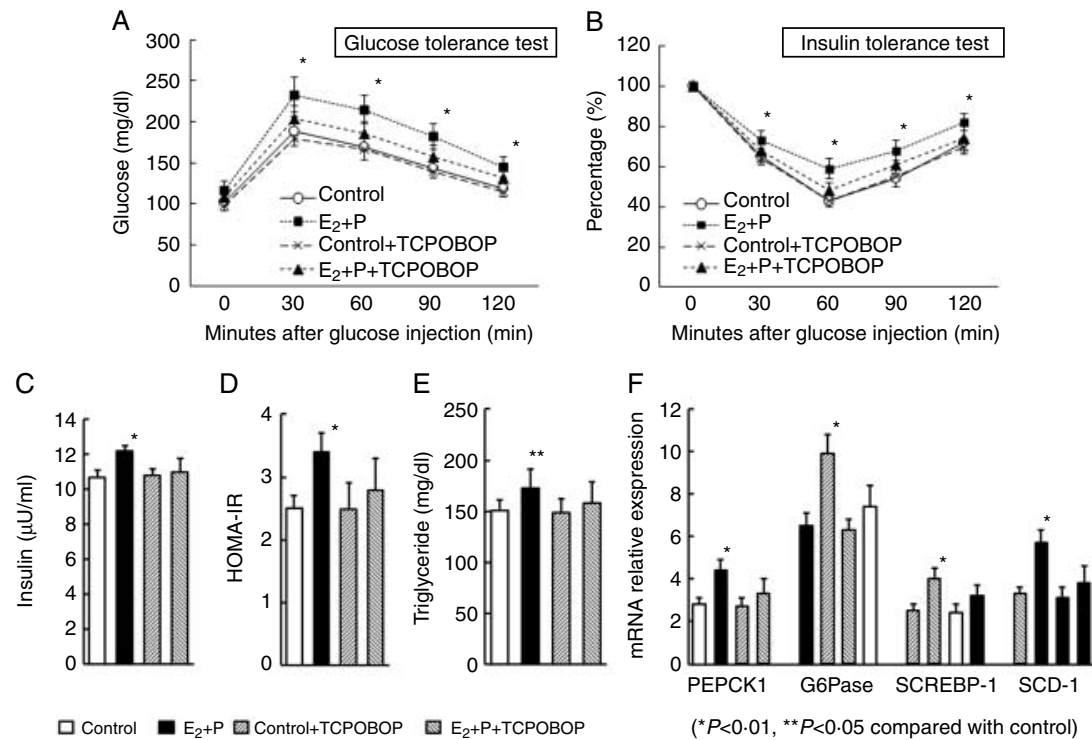

Figure 1 CAR activation ameliorates sex steroid-induced glucose intolerance and insulin resistance in oophorectomized mice treated with high concentration of sex steroids. (A-E) Treatment with TCPOBOP $(0.5 \mathrm{mg} / \mathrm{kg}$ per week) ameliorates the glucose intolerance and insulin resistance induced by sex steroid $\left(E_{2}+\right.$ progesterone $\left.(P)\right)$ treatment in oophorectomized mice, as determined by the GTT (A), ITT (B), fasting insulin level (C), HOMA-IR (D), and total triglyceride level (E). (F) The mRNA expression of genes involved in gluconeogenesis and lipogenesis were measured by real-time PCR analysis of liver extracts from non-pregnant mice treated with corn oil (control), sex steroid or a combination of sex steroid, and TCPOBOP. The results represent means \pm S.D. ( $n=6$ per group). ${ }^{\star} P<0.01,{ }^{\star} P<0.05$ versus corn oil-treated oophorectomized mice. 


\section{Statistical analysis}

Statistical analyses were performed by one-way ANOVA followed by Dunnett's test. Data are presented as the mean \pm s.D. Values of $P<0.05$ were considered to indicate statistical significance.

\section{Results}

\section{CAR activation improves $E_{2}$ and progesterone- induced glucose intolerance and insulin resistance in non-pregnant mice}

To test whether relatively high levels of sex steroid, $\mathrm{E}_{2}$ and progesterone, which are compatible with physiological levels in normal pregnant mice, impair the glucose metabolism and whether CAR activation improves the $\mathrm{E}_{2^{-}}$and progesterone-induced glucose intolerance, we performed GTT and ITT in oophorectomized mice treated with $\mathrm{E}_{2}$ and progesterone. We used TCPOBOP, which was shown to specifically bind to mouse CAR and to regulate the target genes (Sueyoshi et al. 1999) as a ligand for CAR. $E_{2^{-}}$and progesterone-treated mice exhibited significantly poorer glucose tolerance than corn oiltreated (control) mice, while TCPOBOP treatment improved the glucose tolerance in $\mathrm{E}_{2^{-}}$and progesterone-treated oophorectomized mice in the GTT (Fig. 1A) and ITT (Fig. 1B). The fasting insulin level, HOMA-IR, and total triglyceride level were increased in $\mathrm{E}_{2}$ and progesterone-treated oophorectomized mice, while TCPOBOP treatment decreased the fasting insulin level, HOMA-IR, and total triglyceride level (Fig. 1C-E). The gluconeogenic genes PEPCK1 and G6Pase and the lipogenic genes $S R E B P-1$ and $S C D-1$ were significantly increased in the liver of oophorectomized mice treated with $\mathrm{E}_{2}$ and progesterone, while ТСРОВOP treatment decreased the expression of these genes (Fig. 1F). There were no significant effects of TCPOBOP on insulin sensitivity and the expression of gluconeogenic and lipogenic genes in corn oil-treated control mice (Fig. 1A-F). Moreover, HOMA-IR was significantly increased in $\mathrm{E}_{2^{-}}$or progesterone-treated oophorectomized mice $\left(\mathrm{E}_{2} ; 3 \cdot 0 \pm 0 \cdot 2\right.$ and progesterone; $\left.3 \cdot 2 \pm 0 \cdot 3\right)$ compared with corn oil-treated mice (control; $2 \cdot 5 \pm 0 \cdot 2$ ) and $\mathrm{E}_{2}$ or progesterone treatment-induced changes were restored by TCPOBOP. We also observed similar results in

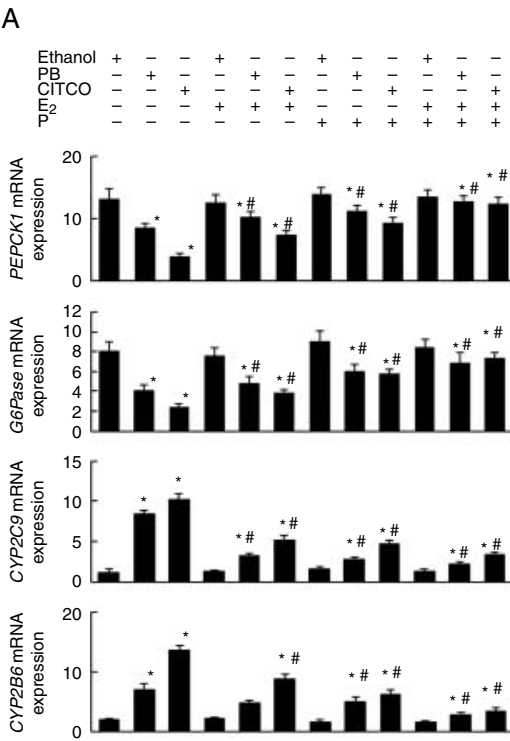

$\left({ }^{*} P<0.01\right.$ compared with EtOH, ${ }^{\#} P<0.01$ compared with $\mathrm{CITCO}$ or $\left.\mathrm{PB}\right)$
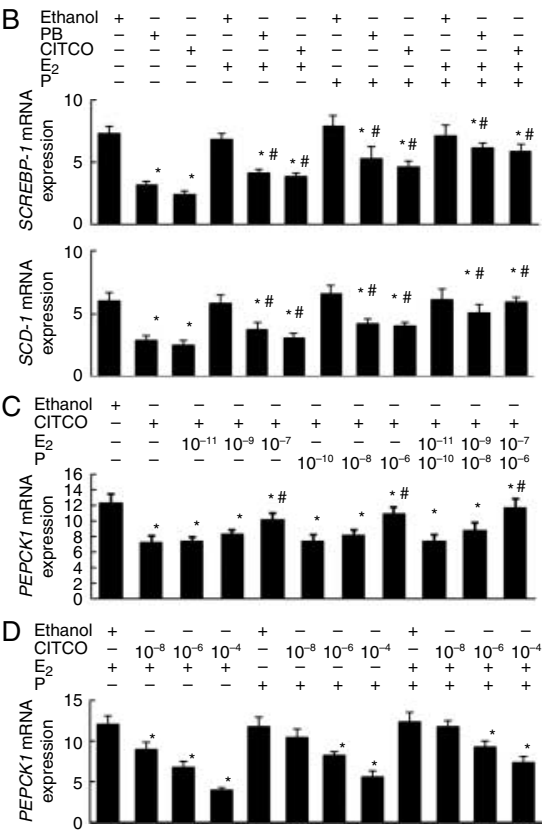

Figure 2 Effects of sex steroid on the expression levels of gluconeogenic and lipogenic genes in the presence or absence of CAR ligands ( $A$ and $B$ ) and in a

concentration-dependent manner ( $C$ and $D)$. HepG2 cells were treated with ethanol vehicle (control), phenobarbital (PB, $1 \mathrm{mM}$ or indicated concentration) or 6-(4-chlorophenyl)imidazo $[2,1 \mathrm{~b}][1,3]$ thiazole-5-carbaldehyde 0 -(3,4-dichlorobenzyl)oxime (CITCO, $1 \mu \mathrm{M}$ or indicated concentration), with or without $17 \beta$-estradiol $\left(E_{2}, 100 \mathrm{nM}\right.$ or indicated concentration), and/or progesterone (P, $1 \mu \mathrm{M}$ or indicated concentration) for $24 \mathrm{~h}$. Total RNA was obtained from the cells and analyzed for the mRNA expression of PEPCK, G6Pase, SREBP-1, SCD-1, $C Y P 2 C 9$, and CYP2B6 by real-time quantitative PCR. The mRNA levels were normalized by the $\beta$-actin mRNA levels. The results represent means \pm s.D. from three independent experiments. ${ }^{*} P<0.01$ versus the controls; ${ }^{\#} P<0.01$ versus CITCO or PB. 
GTT and ITT and there seems to be robust effects by progesterone compared with $\mathrm{E}_{2}$, while the combination of $\mathrm{E}_{2}$ and progesterone had more strong effect on glucose metabolism (data not shown).

\section{Effects of $E_{2}$ and/or progesterone on the expression of gluconeogenic and lipogenic genes in the presence or absence of CAR ligands}

We evaluated human hepatoma HepG2 cells because native CAR was expressed in this cell line (data not shown). CITCO, which directly interacts with CAR, was used as a CAR ligand and PB, which does not directly interact with CAR, was also used as a CAR activator because they have been shown to activate the CARmediated pathway (Sueyoshi et al. 1999, Maglich et al. 2003, Swales \& Negishi 2004). The mRNA expression of the gluconeogenic genes PEPCK and G6Pase were significantly decreased in the presence of CAR ligands, while the mRNA expression of CYP2C9 and CYP2B6, which is a target gene for human CAR (Kawamoto et al. 2000, Ferguson et al. 2002), was significantly increased in the presence of PB or CITCO compared with ethanol treatment as a control. In addition, $\mathrm{E}_{2}$ and/or progesterone treatment significantly increased the PEPCK and G6Pase mRNA and decreased the CYP2C9 and $C Y P 2 B 6$ mRNA expression with $\mathrm{PB}$ or CITCO (Fig. 2A). The mRNA expression of SREBP-1 and SCD-1 were significantly decreased in the presence of CAR ligands compared with ethanol treatment, while sex steroid treatment significantly increased the SREBP-1 and SCD-1 mRNA expression with PB or CITCO (Fig. 2B). And there seem to be robust effects by progesterone compared with $\mathrm{E}_{2}$, while the combination of $\mathrm{E}_{2}$ and progesterone had a stronger effect in the presence of PB or CITCO (Fig. 2A and B). The effect of $\mathrm{E}_{2}$ and/or progesterone on the mRNA expression of PEPCK was concentration-dependent (Fig. 2C). We also observed a concentration-dependent effect of CITCO on the PEPCK mRNA expression in the presence of $\mathrm{E}_{2}$ and/or progesterone (Fig. 2D).

\section{Effects of $E_{2}$ and/or progesterone on CAR-mediated transcription in the presence or absence of CAR ligands}

Next, we introduced the transient reporter assay to examine which stage in CAR-mediated signaling $\mathrm{E}_{2}$ and progesterone affected. Reporter gene constructs, (NR1) ${ }^{3}$-tk-CAT or tk-CAT, were introduced into HepG2 cells. Treatment with PB or CITCO significantly activated CAR-mediated transcription in HepG2 cells using (NR1) ${ }^{3}$-tk-CAT (Fig. 3). $\mathrm{E}_{2}$ and/or progesterone treatment had no effect on this transcription. There were no non-specific activations with either ligand in the cells transfected with tk-CAT. In addition, we observed significant decreases in CARmediated transcription in the presence of $\mathrm{E}_{2}$ and/or progesterone with $\mathrm{PB}$ or CITCO compared with transcription without sex steroid, while progesterone had more robust effect on transcription.

\section{Effects of CAR siRNAs on the mRNA expression of G6Pase, SREBP-1, CYP2C9, and CYP2B6 and CAR-mediated transcription in the presence of CAR ligands with or without $E_{2}$ or progesterone}

To investigate the effects of CAR siRNAs on the mRNA expression levels of G6Pase, SREBP-1, CYP2C9, and CYP2B6 in the presence of CAR ligands with or without sex steroid, $\mathrm{E}_{2}$ or progesterone, we qualitatively examined the mRNA levels of these genes in HepG2 cells. We confirmed the efficacy of the CAR siRNAs for knockdown of CAR mRNA expression in HepG2 cells by RT-PCR and western blotting. Neither CAR mRNA nor CAR protein was detected in HepG2 cells transfected with the CAR siRNAs (Fig. 4A). In CAR siRNA-treated cells, there were no significant decreases in the G6Pase and SREBP-1 mRNA levels, nor was there a significant increase in the CYP2C9 and CYP2B6 mRNA level in the presence of CAR ligands PB and CITCO, compared with control siRNA-treated cells (Fig. 4B). Suppression of the ligand-induced effects on target gene expression by $\mathrm{E}_{2}$ or progesterone was not observed in cells transfected with the CAR siRNAs. Next, we examined the effects of the CAR siRNAs on CAR-mediated transcription. The reporter gene constructs, (NR1) ${ }^{3}$ tk-CAT or tk-CAT, were introduced into HepG2 cells. In

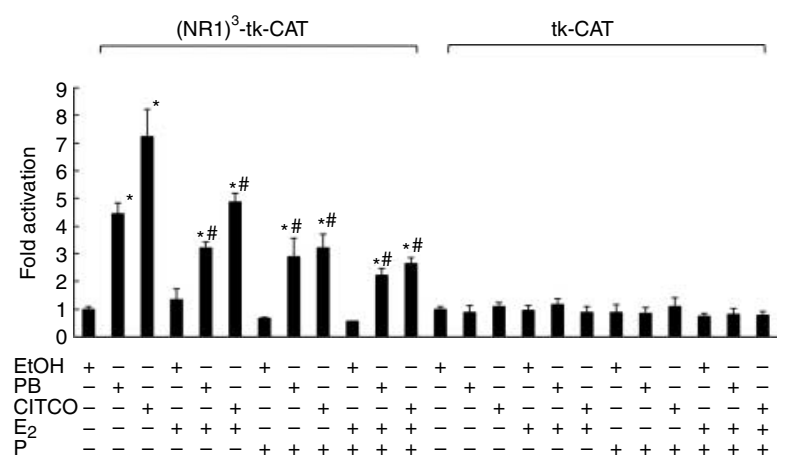

Figure 3 Effects of sex steroid on CAR-mediated transcription in the presence or absence of CAR ligands. HepG2 cells were cotransfected with $1 \mu \mathrm{g}$ of a reporter gene construct, (NR1) ${ }^{3}$ tk-chloramphenicol acetyl transferase (CAT) or tk-CAT. The cells were treated with ethanol $(\mathrm{EtOH}$, control), phenobarbital (PB, $1 \mathrm{mM}$ ) or 6-(4-chlorophenyl)imidazo [2,1b] [1,3]thiazole-5-carbaldehyde $O$-(3,4-dichlorobenzyl)oxime (CITCO, $1 \mu \mathrm{M})$, with or without $17 \beta$-estradiol $\left(E_{2}, 100 \mathrm{nM}\right)$, or progesterone $(P, 1 \mu \mathrm{M})$ for $36 \mathrm{~h}$. The CAT levels were determined using a CAT ELISA kit. The results represent means \pm s.D. from three independent experiments. ${ }^{*} P<0.01$ versus the ethanol control; ${ }^{\#} P<0.01$ versus CITCO or PB. 

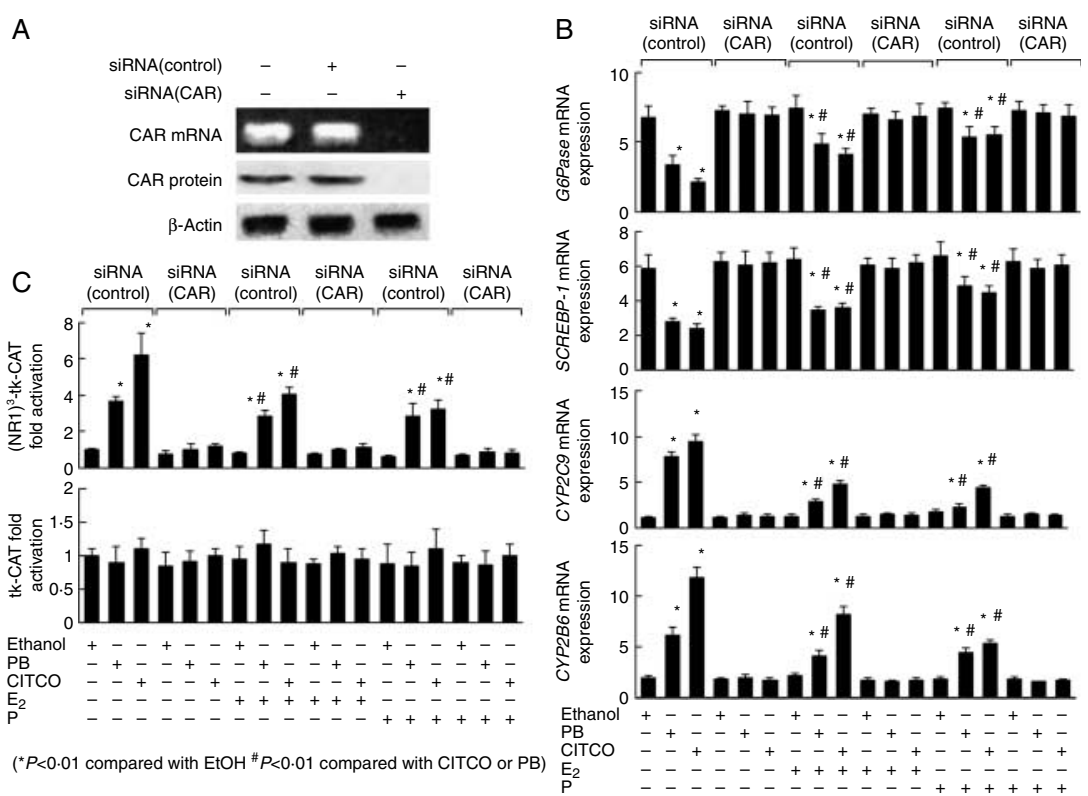

Figure 4 Effects of CAR siRNAs on the mRNA expression of G6Pase, SREBP-1, CYP2C9, and CYP2B6, and on CAR-mediated transcription in the presence of CAR ligands with or without sex steroid. (A) HepG2 cells were transfected with CAR or control siRNAs. Whole cell extracts were prepared, and the CAR protein levels were determined by western blotting using anti-CAR antibodies. Total RNA was also obtained from the cells and analyzed for the expression of CAR mRNA by RT-PCR. The PCR products were separated in $3 \%$ agarose gels and visualized by ethidium bromide staining. (B) HepG2 cells were transfected with CAR or control siRNAs and treated with ethanol (control), phenobarbital (PB, $1 \mathrm{mM})$ or 6-(4-chlorophenyl)imidazo [2,1b] [1,3]thiazole-5-carbaldehyde 0 -(3,4dichlorobenzyl)oxime (CITCO, $1 \mu \mathrm{M})$, with or without $17 \beta$-estradiol $\left(E_{2}, 100 \mathrm{nM}\right)$, or progesterone $(P, 1 \mu \mathrm{M})$ for $24 \mathrm{~h}$. Total RNA was obtained from the cells and analyzed for the mRNA expression of G6Pase, SREBP-1, CYP2C9, and CYP2B6 by real-time quantitative PCR. The mRNA levels were normalized by the $\beta$-actin mRNA levels. (C) HepG2 cells were cotransfected with CAR or control siRNAs and $1 \mu \mathrm{g}$ of a reporter gene construct, $(\mathrm{NR} 1)^{3}$-tk- chloramphenicol acetyl transferase (CAT) or tk-CAT. The cells were treated with ethanol (control), PB $(1 \mathrm{mM})$ or CITCO $(1 \mu \mathrm{M})$, with or without $\mathrm{E}_{2}$ $(100 \mathrm{nM})$, or progesterone $(\mathrm{P})(1 \mu \mathrm{M})$ for $36 \mathrm{~h}$. The amount of CAT was determined using a CAT ELISA kit. The results represent means \pm S.D. from three independent experiments. ${ }^{\star} P<0.01$ versus the controls; ${ }^{\#} P<0.01$ versus CITCO or PB.

control siRNA-transfected cells, PB and CITCO significantly activated the native CAR-mediated transcription, and these effects were significantly suppressed by $\mathrm{E}_{2}$ or progesterone. No CAR-mediated transactivation was observed in the presence of $\mathrm{PB}$ or CITCO in the CAR siRNA-transfected cells, even in the presence of $\mathrm{E}_{2}$ or progesterone. No non-specific effects of the siRNAs on transcription were observed, since there were no differences in basal transcription using the tk-CAT vector between the CAR siRNA- and control siRNAtransfected cells (Fig. 4C).

\section{Effects of $E_{2}$ and/or progesterone on the interactions of transcription factors with CAR/NR1 complexes}

We examined which transcription factors were recruited by CAR/NR1 complexes and the effects of sex steroid on the interactions of these transcription factors with
CAR/NR1 complexes using a DNA affinity immunoblotting assay. Since CAR-mediated gene regulation has been shown to require SRC-1 (Muangmoonchai et al. 2001), we examined whether SRC-1 was associated with $\mathrm{CAR} / \mathrm{NR} 1$ complexes in the presence of CAR ligands with or without $\mathrm{E}_{2}$ and/or progesterone. FOXO1 and HNF $4 \alpha$ were also examined because these transcription factors, which play important roles in gluconeogenesis, interact directly with CAR (Kodama et al. 2004). SRC-1 was strongly detected on the NR1 element in the presence of CAR ligands, but was much less strongly detected in the presence of CAR ligands with $\mathrm{E}_{2}$ and/or progesterone. No SRC-1 was detected in controls treated with vehicle alone. In addition, we observed a strong association of FOXO1 and HNF4 $4 \alpha$ on the NR1 element in the presence of CAR ligands, with a much lower association of these transcription factors in the presence of CAR ligands with $\mathrm{E}_{2}$ and/or progesterone. No other 

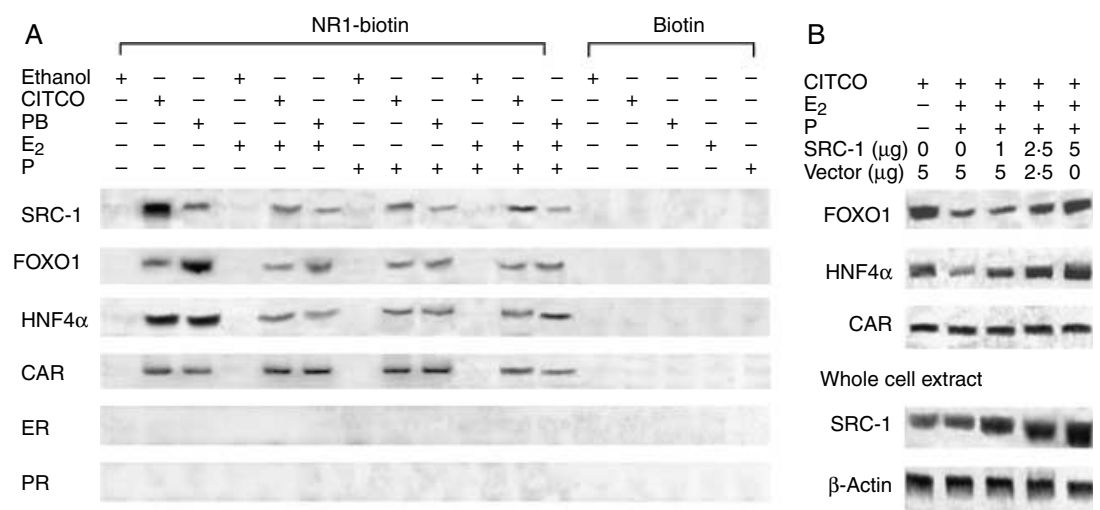

Figure 5 Effects of sex steroid on the interactions of transcription factors with CAR/NR1 complexes. (A) Aliquots $(200 \mu \mathrm{g})$ of nuclear extracts obtained from HepG2 cells were incubated with a DNA binding reaction mixture including biotin-labeled NR1 and treated with ethanol (control), phenobarbital (PB, $1 \mathrm{mM})$ or 6-(4-chlorophenyl)imidazo $[2,1 \mathrm{~b}][1,3]$ thiazole-5-carbaldehyde $O$-(3,4-dichlorobenzyl)oxime (CITCO, $1 \mu \mathrm{M})$, with or without $17 \beta$ estradiol ( $\left.E_{2}, 100 \mathrm{nM}\right)$, and/or progesterone $(P, 1 \mu \mathrm{M})$. (B) For rescue experiments, various amounts of pcDNA3-steroid receptor coactivator (SRC-1) or pcDNA3 vector were also transfected. DNA/protein complexes were captured with $0.1 \mathrm{mg}$ of magnetic streptavidin beads at $4{ }^{\circ} \mathrm{C}$ for $30 \mathrm{~min}$. The beads were drawn into a pellet using a magnet and washed three times with DNA binding buffer. The bound proteins were eluted from the magnetic beads by heating and analyzed by western blotting using a goat polyclonal antibody against $\mathrm{CAR}$ and rabbit polyclonal antibodies against SRC-1, FOXO1, HNF $4 \alpha, \mathrm{ER} \alpha$, and PR.

nuclear receptor, $\mathrm{ER} \alpha$, was detected in these assays (Fig. 5A). Moreover, overexpression of SRC-1 rescued the decreased association of FOXO1 and HNF $4 \alpha$ on the NR1 element in a dose-dependent manner (Fig. 5B).

\section{Recruitment analysis of CAR, FOXO1 and HNF4 $\alpha$ on the CAR responsive element and $\mathrm{HNF} 4 \alpha$ and FOXO1 on their responsive element}

ChIP assays were performed on the chromatin extracts from the HepG2 cells to examine the effect of CAR ligand and sex steroids, $\mathrm{E}_{2}$ and progesterone, on the recruitment of CAR, FOXO1 and HNF $4 \alpha$ on the CAR responsive element in CYP2C9 promoter (Surapureddi et al. 2008), HNF4 $\alpha$ on the HNF4 $\alpha$ responsive element in the PEPCK promoter (Bhalla et al. 2004), and FOXO1 on the FOXO1 binding site in the G6Pase promoter (Vander Kooi et al. 2003). CAR ligand CITCO enhanced the recruitment of CAR, FOXO1, HNF4 $\alpha$, and coactivator SRC-1 compared with ethanol treatment, but $\mathrm{E}_{2}$ and/or progesterone decreased these recruitments on the CAR responsive element (Fig. 6A). Other nuclear receptor, ER and PR, and non-specific binding were not detected in this assay. We also observed the effect of CITCO and sex steroids, $\mathrm{E}_{2}$ and/or progesterone on the recruitment of HNF4 $\alpha$ responsive element in the PEPCK promoter and FOXO1 on the FOXO1 binding site in the G6Pase promoter. The recruitment of HNF $4 \alpha$ and FOXO1 on their responsive element was decreased in the presence of CITCO, but the addition of $\mathrm{E}_{2}$ and/or progesterone augmented the recruitment of FOXO1 and HNF $4 \alpha$ on their responsive element, respectively, and progesterone had more strong effect on the recruitments (Fig. 6B).

\section{Discussion}

The sex steroid, $\mathrm{E}_{2}$ and progesterone may be involved in the gestation-induced insulin resistance, since relatively high concentrations of $\mathrm{E}_{2}(100-200 \mathrm{pg} / \mathrm{ml})$ and progesterone $(100-200 \mathrm{ng} / \mathrm{ml})$, which are within physiological ranges during pregnancy in their in vivo experiments, reduce insulin sensitivity (Ryan \& Enns 1988, Livingstone \& Collison 2002, Barros et al. 2008). Because the elevations of both $\mathrm{E}_{2}$ and progesterone were observed during pregnancy, we examined whether treatment of $\mathrm{E}_{2}$ and progesterone would affect glucose tolerance, insulin sensitivity using GTT, ITT, and HOMA-IR and the expression of the hepatic gluconeogenic enzymes PEPCKand G6Pase (Ueda et al. 2002, Gao et al. 2009) and lipogenic enzymes SREBP-1 and SCD-1 (Roth et al. 2008, Dong et al. 2009, Gao et al. 2009) in oophorectomized mouse. We also examined whether CAR activation would improve insulin sensitivity and enzyme expression levels in oophorectomized mice treated with $\mathrm{E}_{2}$ and progesterone because CAR activation has been shown to improve insulin sensitivity in non-pregnant mice using a high-fat diet-induced model of diabetes and in leptin-deficient $(o b / o b)$ mice (Dong et al. 2009, Gao et al. 2009). We observed that relatively high-dose treatment with $\mathrm{E}_{2}$ and progesterone, which induced the elevated concentration of $\mathrm{E}_{2}$ and 

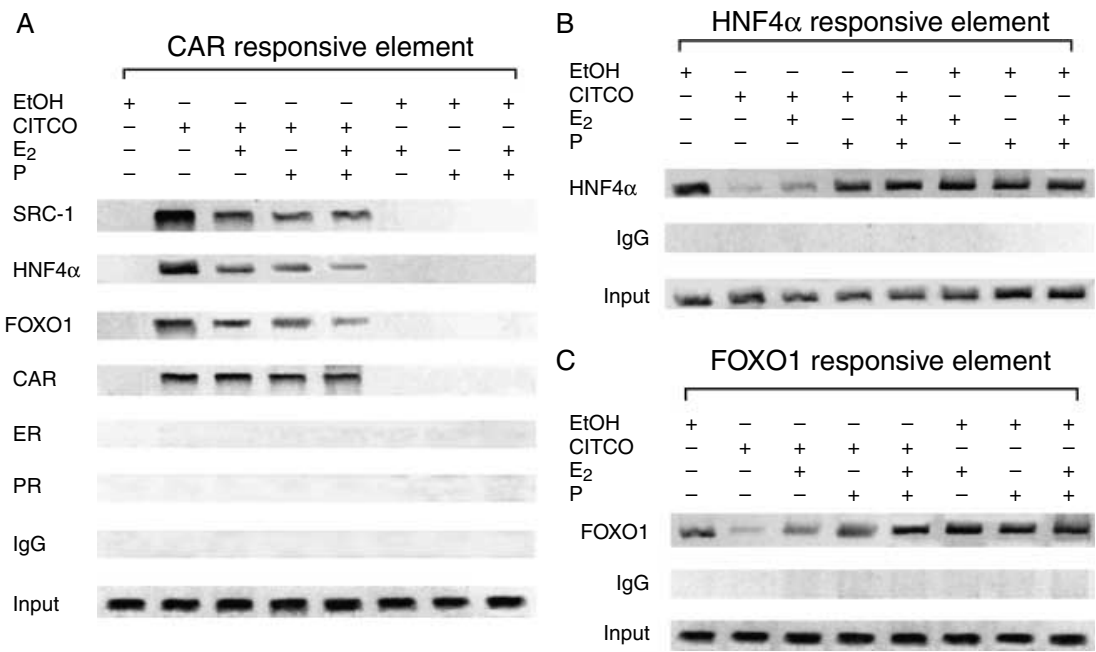

Figure 6 Recruitment analyses of CAR, FOXO1, and HNF4 $\alpha$ on the CAR responsive element and HNF $4 \alpha$ and FOXO1 on their responsive element by ChIP assay. ChIP assays were performed on the chromatin extracts from the HepG2 cells to examine the effect of CAR ligand and sex steroids, $E_{2}$ and progesterone $(P)$, on the recruitment of CAR, FOXO1, and HNF4 $\alpha$ on the CAR responsive element in the CYP2C9 promoter (A), the $\mathrm{HNF} 4 \alpha$ responsive element in the PEPCK promoter $(\mathrm{B})$ and the FOXO1 binding site in the G6Pase promoter (C). HepG2 cells were grown to $90 \%$ confluent, were treated with ethanol $(\mathrm{EtOH})$ vehicle alone or with 6-(4-chlorophenyl)imidazo [2,1b] [1,3]thiazole-5-carbaldehyde $O$-(3,4-dichlorobenzyl)oxime $(\mathrm{CITCO}, 1 \mu \mathrm{M})$, with or without $17 \beta$-estradiol $\left(\mathrm{E}_{2}, 100 \mathrm{nM}\right)$, and/or progesterone $(\mathrm{P}, 1 \mu \mathrm{M})$ for $48 \mathrm{~h}$, were incubated with $1 \%$ formaldehyde at room temperature for $10 \mathrm{~min}$ and subjected to sonication to reduce DNA length to $0 \cdot 3-1 \cdot 0 \mathrm{~kb}$. Chromatin was precleared in the presence of $20 \mu \mathrm{l}$ of normal serum, $2 \mu \mathrm{g}$ of salmon sperm DNA, and $80 \mu \mathrm{l}$ of a $25 \%$ protein A-agarose slurry. Precleared chromatin samples were subjected to immunoprecipitation in the presence of $2 \mu \mathrm{g}$ of goat polyclonal antibody against CAR or rabbit polyclonal antibodies against SRC-1, FOXO1, HNF4 $\alpha$, ER $\alpha$ or PR, or nonimmune rabbit IgG. After collecting the complex by incubation with $60 \mu \mathrm{l}$ of a $25 \%$ protein ASepharose slurry and centrifugation, the beads were washed five times, and the chromatin immune complex was eluted. After reversing the cross-links, DNA was purified and used as a template in PCR. PCR was performed by primer sets specific for CAR responsive element in the CYP2C9 promoter, HNF4 responsive element in the PEPCK promoter and the FOXO1 binding sites in the G6Pase promoter.

progesterone within the normal physiological range during pregnancy, induced glucose intolerance and insulin resistance with increased expression levels of gluconeogenic and lipogenic enzymes. Moreover, CAR activation improved the glucose tolerance, insulin sensitivity, and lipid metabolism with suppression of these enzymes. Thus, our data suggested that the relatively high concentrations of sex steroids, $\mathrm{E}_{2}$ (70$80 \mathrm{pg} / \mathrm{ml}$ ) and progesterone $(80-90 \mathrm{ng} / \mathrm{ml})$, which were compatible with physiological range during pregnancy in ICR mice tested in this study may participate in the induction of insulin resistance via the suppression of CAR-mediated signaling. Our data also demonstrated that CAR activation may serve to improve insulin sensitivity under physiological concentrations of $\mathrm{E}_{2}$ and progesterone during pregnancy and that the metabolic benefit of CAR activation may have resulted from the combined inhibition of gluconeogenesis and lipogenesis.

Recent data have strongly suggested that CAR activation repressed the gluconeogenic pathway by interfering with transcription factors or cofactors involved in the transcriptional regulation of gluconeogenic enzymes (Kodama et al. 2004, Miao et al. 2006). FOXO1 is a key positive regulator of gluconeogenesis. CAR can bind physically to FOXO1 and suppress the association between FOXO1 and the insulin-responsive element in gluconeogenic enzyme promoters such as PEPCK (Kodama et al. 2004). HNF4 $\alpha$ is also a positive regulator of gluconeogenesis. CAR inhibits gluconeogenic enzyme gene expression by competing with $\mathrm{HNF} 4 \alpha$ for binding to the DR1 motif in the promoter region of gluconeogenic enzyme genes (Miao et al. 2006). Moreover, CAR has been shown to repress the transcriptional activation of $\mathrm{ER} \alpha$ by squelching p160 coactivators including SRC-1 (Min et al. 2002). In this study, we observed that high $\mathrm{E}_{2}$ and/or progesterone conditions enhanced gluconeogenic and lipogenic gene expression levels in a concentration-dependent manner and reduced the associations of SRC-1, FOXO1, and HNF4 $\alpha$ with NR1/CAR complexes in the presence of CAR ligands. 
Moreover, overexpression of SRC-1 rescued the decreased associations of FOXO1 and HNF4 $\alpha$ with NR1/CAR complexes with high concentrations of $E_{2}$ and/or progesterone. In addition, ChIP assay demonstrated that CAR ligand CITCO enhanced the recruitment of CAR, FOXO1, HNF4 $\alpha$, and coactivator SRC-1, but $\mathrm{E}_{2}$ and/or progesterone suppressed the recruitments on the CAR responsive element. We also observed the effect of CITCO and sex steroids, $\mathrm{E}_{2}$ and/or progesterone on the recruitment of $\mathrm{HNF} 4 \alpha$ and FOXO1 on their responsive element in the promoter of PEPCK and G6Pase. The recruitment of FOXO1 and HNF $4 \alpha$ on their responsive element was decreased in the presence of CITCO and the addition of $\mathrm{E}_{2}$ and/or progesterone augmented the recruitment of $\mathrm{HNF} 4 \alpha$ and FOXO1 on their responsive element. These data suggest that squelching of coactivators including SRC-1 under high $\mathrm{E}_{2}$ and/or progesterone conditions may inhibit the interactions of CAR with HNF $4 \alpha$ and FOXO1 on CAR responsive element and augment the association of these factors on the promoter of gluconeogenic factors, thereby resulting in increased gluconeogenesis.

We observed that CITCO had more predominant effects on CAR signaling compared with PB. CITCO has high affinity for CAR and directly binds to CAR (Maglich et al. 2003), but $P B$ has very low affinity and promotes CAR translocation into nucleus without direct binding (Swales \& Negishi 2004), which might results in different levels of effects by CITCO or PB. And there were not significant but robust effects by progesterone compared with $\mathrm{E}_{2}$, while the combination of $\mathrm{E}_{2}$ and progesterone had more strong effect in the presence of PB or CITCO. Because different coactivators have been demonstrated to play some roles in ER- and PR-mediated transcription (Glass \& Rosenfeld 2000), the different squelching of various coactivators might occur with $\mathrm{E}_{2}$ and/or progesterone treatment, which results in the differences between $\mathrm{E}_{2}$ and progesterone. Moreover, Kawamoto et al. (2000) demonstrated that $10 \mu \mathrm{M}$ of $\mathrm{E}_{2}$ activated CAR-mediated transcription and enhanced nuclear accumulation in mouse. Because we used relatively lower $\mathrm{E}_{2}$ concentration in mouse compared with previous report (Kawamoto et al. 2000), we might not observed the effect of $\mathrm{E}_{2}$ on CAR-mediated signaling. In addition, the effects of $\mathrm{E}_{2}$ and/or progesterone on gluconeogenic and lipogenic genes in HepG2 cells were observed only in the presence of CAR ligand, suggesting that $\mathrm{E}_{2}$ and progesterone might affect these genes only under CAR activation by endogenous ligand in vivo. Because our data included several differences between in vitro and in vivo experiments in hormone levels and ICR mice and human cell lines, further analysis will be required for these speculations.

In this study, we observed that the relatively high $\mathrm{E}_{2}$ and progesterone concentrations in the normal physiological range during pregnancy induced glucose intolerance and insulin resistance in oophorectomized mice, and that the CAR ligand TCPOBOP rescued this abnormal glucose metabolism with decreased expression of gluconeogenic and lipogenic genes. Our data suggest that the activation of CAR may ameliorate the insulin resistance under the relatively high concentrations of sex steroids, $\mathrm{E}_{2}$ and progesterone, which are compatible with the physiological range during pregnancy, via decreased activity of transcription factors in gluconeogenesis together with CAR and that CAR might be a potential therapeutic target for pregnancy-induced insulin resistance. In addition, because an increase in insulin resistance during pregnancy contributes to the development of gestational diabetes mellitus and preeclampsia (Kaaja et al. 1999, Seely \& Solomon 2003, Kaaja \& Greer 2005), we are examining whether CAR activation can ameliorate the glucose metabolism and signs of preeclampsia by improving insulin resistance using obese pregnant mice.

\section{Declaration of interest}

The authors declare that there is no conflict of interest that could be perceived as prejudging the impartiality of the research reported.

\section{Funding}

This work was supported in part by research grants from the Ministry of Education, Culture, Sports, Science and Technology of Japan (17591739 and 22591856).

\section{References}

Baes M, Gulick T, Choi HS, Martinoli MG, Simha D \& Moore DD 1994 A new orphan member of the nuclear hormone receptor superfamily that interacts with a subset of retinoic acid response elements. Molecular and Cellular Biology 14 1544-1552.

Barros RP, Morani A, Moriscot A \& Machado UF 2008 Insulin resistance of pregnancy involves estrogen-induced repression of muscle GLUT4. Molecular and Cellular Endocrinology 295 24-31. (doi:10.1016/j.mce.2008.07.008)

Bhalla S, Ozalp C, Fang S, Xiang L \& Kemper JK 2004 Ligand-activated pregnane $\mathrm{X}$ receptor interferes with HNF-4 signaling by targeting a common coactivator PGC-1 $\alpha$. Journal of Biological Chemistry 279 45139-45147. (doi:10.1074/jbc.M405423200)

Butte NF 2000 Carbohydrate and lipid metabolism in pregnancy: normal compared with gestational diabetes mellitus. American Journal of Clinical Nutrition 7 1256S-1261S.

Catalano PM, Tyzbir ED, Roman NM, Amini SB \& Sims EA 1991 Longitudinal changes in insulin release and insulin resistance in nonobese pregnant women. American Journal of Obstetrics and Gynecology 165 1667-1682.

Choi HS, Chung M, Tzameli I, Simha D, Lee YK, Seol W \& Moore DD 1997 Differential transactivation by two isoforms of the orphan nuclear hormone receptor CAR. Journal of Biological Chemistry 272 23565-23571. (doi:10.1074/jbc.272.38.23565)

Cunningham FG, Leveno KJ, Bloom SL, Hauth JC, Rouse DJ \& Spong CY (Eds) 2010 Maternal physiology. In Williams Obstetrics, 23rd edn, pp 107-135. New York: McGraw-Hill. 
Dong B, Saha PK, Huang W, Chen W, Abu-Elheiga LA, Wakil SJ, Stevens RD, Ilkayeva O, Newgard CB, Chan L et al. 2009 Activation of nuclear receptor CAR ameliorates diabetes and fatty liver disease. PNAS 106 18831-18836. (doi:10.1073/pnas.0909731106)

Ferguson SS, LeCluyse EL, Negishi M \& Goldstein JA 2002 Regulation of human CYP2C9 by the constitutive androstane receptor: discovery of a new distal binding site. Molecular Pharmacology 62 737-746. (doi:10.1124/mol.62.3.737)

Freemark M 2006 Regulation of maternal metabolism by pituitary and placental hormones: roles in fetal development and metabolic programming. Hormone Research 65 41-49. (doi:10.1159/000091505)

Gao J, He J, Zhai Y, Wada T \& Xie W 2009 The constitutive androstane receptor is an anti-obesity nuclear receptor that improves insulin sensitivity. Journal of Biological Chemistry 284 25984-25992. (doi:10. 1074/jbc.M109.016808)

Glass CK \& Rosenfeld MG 2000 The coregulator exchange in transcriptional functions of nuclear receptors. Genes and Development 14 121-141. (doi:10.1101/gad.14.2.121)

Honkakoski P, Zelko I, Sueyoshi T \& Negishi M 1998 The nuclear orphan receptor CAR-retinoid $\mathrm{X}$ receptor heterodimer activates the phenobarbital-responsive enhancer module of the CYP2B gene. Molecular and Cellular Biology 18 5652-5658.

Huang W, Zhang J, Chua SS, Qatanani M, Han Y, Granata R \& Moore DD 2003 Induction of bilirubin clearance by the constitutive androstane receptor (CAR). PNAS 100 4156-4161. (doi:10.1073/pnas.0630614100)

Kaaja RJ \& Greer IA 2005 Manifestations of chronic disease during pregnancy. Journal of the American Medical Association 294 2751-2757. (doi:10.1001/jama.294.21.2751)

Kaaja R, Laivuori H, Laakso M, Tikkanen MJ \& Ylikorkala O 1999 Evidence of a state of increased insulin resistance in preeclampsia. Metabolism 48 892-896. (doi:10.1016/S0026-0495(99)90225-1)

Kawamoto T, Kakizaki S, Yoshinari K \& Negishi M 2000 Estrogen activation of the nuclear orphan receptor CAR (constitutive active receptor) in induction of the mouse Cyp2b10 gene. Molecular Endocrinology 14 1897-1905. (doi:10.1210/me.14.11.1897)

Kodama S, Koike C, Negishi M \& Yamamoto Y 2004 Nuclear receptor CAR and PXR cross talk with FOXO1 to regulate genes that encode drugmetabolizing and gluconeogenic enzymes. Molecular and Cellular Biology 24 7931-7940. (doi:10.1128/MCB.24.18.7931-7940.2004)

Livingstone C \& Collison M 2002 Sex steroids and insulin resistance. Clinical Science 102 151-166. (doi:10.1042/CS20010197)

Maglich JM, Parks DJ, Moore LB, Collins JL, Goodwin B, Billin AN, Stoltz CA, Kliewer SA, Lambert MH, Willson TM et al. 2003 Identification of a novel human constitutive androstane receptor (CAR) agonist and its use in the identification of CAR target genes. Journal of Biological Chemistry 278 17277-17283. (doi:10.1074/jbc.M300138200)

Masuyama H \& MacDonald PN 1998 Proteasome-mediated degradation of the vitamin D receptor (VDR) and a putative role for SUG1 interaction with the AF-2 domain of VDR. Journal of Cellular Biochemistry 71 429-440. (doi:10.1002/(SICI) 1097-4644(19981201) 71:3<429::AID-JCB11 > 3.0.CO;2-P)

Masuyama H, Hiramatsu Y, Mizutani Y, Inoshita H \& Kudo T 2001 The expression of pregnane $\mathrm{X}$ receptor and its target gene, cytochrome P450 3A1, in perinatal mouse. Molecular and Cellular Endocrinology 172 47-56. (doi:10.1016/S0303-7207(00)00395-6)

Masuyama H, Suwaki N, Tateishi Y, Nakatsukasa H, Segawa T \& Hiramatsu Y 2005 The pregnane X receptor regulates gene expression in a ligand- and promoter-selective fashion. Molecular Endocrinology 19 1170-1180. (doi:10.1210/me.2004-0434)

Masuyama H, Nakatsukasa H \& Hiramatsu Y 2010 Effect of oncostatin $\mathrm{M}$ on uridine diphosphate-5' ${ }^{\prime}$-glucuronosyltransferase $1 \mathrm{Al}$ through crosstalk with constitutive androstane receptor. Molecular Endocrinology 24 745-753. (doi:10.1210/me.2009-0478)

Matthews DR, Hosker JP, Rudenski AS, Naylor BA, Treacher DF \& Turner RC 1985 Homeostasis model assessment: insulin resistance and betacell function from fasting plasma glucose and insulin concentrations in man. Diabetologia 28 412-419. (doi:10.1007/BF00280883)
Miao J, Fang S, Bae Y \& Kemper JK 2006 Functional inhibitory crosstalk between constitutive androstane receptor and hepatic nuclear factor-4 in hepatic lipid/glucose metabolism is mediated by competition for binding to the DR1 motif and to the common coactivators, GRIP-1 and PGC-1alpha. Journal of Biological Chemistry 281 14537-14546. (doi:10.1074/jbc.M510713200)

Min G, Kim H, Bae Y, Petz L \& Kemper JK 2002 Inhibitory cross-talk between estrogen receptor (ER) and constitutively activated androstane receptor (CAR). CAR inhibits ER-mediated signaling pathway by squelching p160 coactivators. Journal of Biological Chemistry 277 34626-34633. (doi:10.1074/jbc.M205239200)

Moore LB, Parks DJ, Jones SA, Bledsoe RK, Consler TG, Stimmel JB, Goodwin B, Liddle C, Blanchard SG, Willson TM et al. 2000 Orphan nuclear receptors constitutive androstane receptor and pregnane $\mathrm{X}$ receptor share xenobiotic and steroid ligands. Journal of Biological Chemistry 275 15122-15127. (doi:10.1074/jbc.M001215200)

Muangmoonchai R, Smirlis D, Wong SC, Edwards M, Phillips IR \& Shephard EA 2001 Xenobiotic induction of cytochrome P450 2B1 (CYP2B1) is mediated by the orphan nuclear receptor constitutive androstane receptor (CAR) and requires steroid co-activator 1 (SRC-1) and the transcription factor Sp1. Biochemical Journal $\mathbf{3 5 5}$ 71-78. (doi:10.1042/0264-6021:3550071)

Roth A, Looser R, Kaufmann M \& Meyer UA 2008 Sterol regulatory element binding protein 1 interacts with pregnane $\mathrm{X}$ receptor and constitutive androstane receptor and represses their target genes. Pharmacogenetics and Genomics 18 325-337. (doi:10.1097/FPC. 0b013e3282f706e 0 )

Ryan EA \& Enns L 1988 Role of gestational hormones in the induction of insulin resistance. Journal of Clinical Endocrinology and Metabolism 67 341-347. (doi:10.1210/jcem-67-2-341)

Seely EW \& Solomon CG 2003 Insulin resistance and its potential role in pregnancy-induced hypertension. Journal of Clinical Endocrinology and Metabolism 88 2393-2398. (doi:10.1210/jc.2003-030241)

Song M, Helguera G, Eghbali M, Zhu N, Zarei MM, Olcese R, Toro R \& Stefani E 2001 Remodeling of Kv4.3 potassium channel gene expression under the control of sex hormones. Journal of Biological Chemistry 276 31883-31890. (doi:10.1074/jbc.M101058200)

Sueyoshi T, Kawamoto T, Zelko I, Honkakoski P \& Negishi M 1999 The repressed nuclear receptor CAR responds to phenobarbital in activating the human CYP2B6 gene. Journal of Biological Chemistry 274 6043-6046. (doi:10.1074/jbc.274.10.6043)

Sugatani J, Kojima H, Ueda A, Kakizaki S, Yoshinari K, Gong QH, Owens IS, Negishi M \& Sueyoshi T 2001 The phenobarbital response enhancer module in the human bilirubin UDP-glucuronosyltransferase UGT1A1 gene and regulation by the nuclear receptor CAR. Hepatology 33 1232-1238. (doi:10.1053/jhep.2001.24172)

Surapureddi S, Rana R, Reddy JK \& Goldstein JA 2008 Nuclear receptor coactivator 6 mediates the synergistic activation of human cytochrome P-450 2C9 by the constitutive androstane receptor and hepatic nuclear factor-4alpha. Molecular Pharmacology 74 913-923. (doi:10.1124/mol.108.048983)

Swales K \& Negishi M 2004 CAR, driving into the future. Molecular Endocrinology 18 1589-1598. (doi:10.1210/me.2003-0397)

Ueda A, Hamadeh HK, Webb HK, Yamamoto Y, Sueyoshi T, Afshari CA, Lehmann JM \& Negishi M 2002 Diverse roles of the nuclear orphan receptor CAR in regulating hepatic genes in response to phenobarbital. Molecular Pharmacology 61 1-6. (doi:10.1124/mol.61.1.1)

Vander Kooi BT, Streeper RS, Svitek CA, Oeser JK, Powel DR \& O'Brien RM 2003 The three insulin response sequences in the glucose-6-phosphatase catalytic subunit gene promoter are functionally distinct. Journal of Biological Chemistry 278 11782-11793. (doi:10.1074/jbc.M212570200)

Received in final form 8 July 2011

Accepted 18 July 2011

Made available online as an Accepted Preprint 18 July 2011 